\title{
Sustentabilidade dos assentamentos no município de Caucaia-CE
}

\author{
Ricardo Candea Sá Barreto ${ }^{1}$ \\ Ahmad Saeed Khan ${ }^{2}$ \\ Patrícia Verônica Pinheiro Sales Lima ${ }^{3}$
}

Resumo: O presente estudo analisou e verificou a importância da sustentabilidade em três assentamentos beneficiados no município de Caucaia pelos programas de reforma agrária tanto em nível federal como estadual no Estado do Ceará. Dado que, apesar dos programas visando implementar a reforma agrária, a pobreza continua, é pertinente mensurar a sustentabilidade dos assentamentos beneficiados pelos programas. Assim, é importante conhecer os benefícios que os recursos alocados nos programas trouxeram para o bemestar das famílias. Os assentamentos federais (INCRA) de Angicos e Boqueirão dos Cunhas e o assentamento estadual de Buíque /Poço Verde(PRAS), foram selecionados para alcançar tal finalidade.Elaborou-se um questionário, contendo uma lista de variáveis, considerando aspectos econômico-sociais, ambientais e de capital social para a mensuração da sustentabilidade. Para tanto, foi criado neste estudo um índice de sustentabilidade (IS), que é a média aritmética de três índices também criados aqui, ou seja, um índice de desenvolvimento econômico-social, um índice ambiental e um índice de capital social. Os valores do Índice de Sustentabilidade sugerem o médio nível de desenvolvimento para os três assentamentos.

\footnotetext{
${ }^{1}$ Mestre em Economia Rural pela UFC e Doutorando em Economia Agrícola pela UFV, e-mail: rcsb@vicosa.ufv.br

${ }^{2}$ Professor Titular do departamento de Economia Agrícola da Universidade Federal do Ceara, bolsista do CNPq e-mail: saeed@ufc.br

${ }^{3}$ Professora Adjunto do departamento de Economia Agrícola da Universidade Federal do Ceara, e-mail: pvpslima@ufc.br
} 
Palavras-chave: Desenvolvimento Sustentável, Assentamentos Rurais, Ceará

\section{Classificação JEL: I38}

Abstract: This study analyzed and verified the importance of sustainability in three land settlements benefited by land reform program of the Federal and State Government in Caucaia county, State of Ceará. It is important to know that the funds allocated to the program did improve the well-being of the favored families. For that, two federal land settlements of "Angicos" and "Boqueirão dos Cunhas" and state land settlement of "Buque/Poço Verde" were selected. A questionnaire containing economic, social, environmental and social capital variables was prepared to measure the sustainability of those settlements. The results built up a sustainability index based on an average of social economic development index, environmental index and social capital index. The value of sustainability index suggested that the three land settlements have a medium development level.

Key words: sustainable development, rural land settlements, Ceará.

\section{JEL Classification: I38}

\section{Introdução}

O Estado do Ceará, de acordo com o WORLD BANK (1999), apresentou, no período de 1970-1997, taxa média anual de crescimento de 5,8\% do PIB. Apesar desse crescimento econômico, a pobreza continua porque os benefícios do crescimento econômico não "deslizam" até os mais pobres. O World Bank observou que cerca de $77 \%$ da população rural do Ceará ainda vive abaixo da linha de pobreza, o que comprova que o crescimento econômico não garante por si só que os pobres sejam beneficiados.

Sensibilizado com a situação mencionada e na tentativa de minorar os problemas e promover estratégias visando o desenvolvimento do setor rural, o governo do Estado do Ceará, no ano de 1995, reformulou o Pro- 
grama de Apoio ao Pequeno Produtor (PAPP), denominando-o Programa de Combate à Pobreza Rural (PCPR), que promove a implementação de ações de desenvolvimento sustentável no estado com participação ativa das comunidades, com vistas a aumentar o acesso das populações rurais mais pobres às atividades de geração de emprego e renda, assim como a provisão de serviços sociais básicos e de infra-estrutura como meios para a redução da pobreza rural.

Um dos componentes do PCPR é o segmento Ação Fundiária, originado a partir da criação, pelo governo do estado, do Fundo Rotativo da Terra (FRT), em outubro de 1996, e em parceria com o Banco Mundial. Surgiu, assim, na forma de projeto piloto, o Programa denominado de Reforma Agrária Solidária. Esse programa se destina a financiar imóveis rurais a trabalhadores sem terra e minifundiários, através das suas associações (KHAN; 2000). Com base nas referências bem sucedidas do Projeto, foram criados Programas em nível federal, tais como: Cédula da Terra, Banco da Terra e PCPR/Crédito Fundiário.

Muitos estudos relativos ao desenvolvimento econômico e social foram elaborados sobre os programas de reforma agrária tanto em nível federal quanto estadual, com maior destaque, o estudo de avaliação de impacto do Programa Cédula da Terra/2001 elaborado pela UNICAMP (2002). Porém, nenhum estudo abordou a questão do capital social e de variáveis ambientais. Assim, este estudo se propõe mensurar a sustentabilidade dos assentamentos beneficiados pelos projetos de reforma agrária pelas políticas de governo federal e estadual no Estado do Ceará considerando aspectos econômico-sociais, ambientais e a mobilização do capital social dentro do projeto, com o intuito de contribuir para diagnosticar possíveis entraves que possam ser superados para a promoção do desenvolvimento rural sustentável.

\subsection{Objetivos}

\subsubsection{Objetivo Geral:}

O objetivo geral deste trabalho é avaliar a sustentabilidade dos assentamentos beneficiados pelos programas de reforma agrária no município de Caucaia no Estado do Ceará. 


\subsubsection{Objetivos Específicos:}

- Avaliar a sustentabilidade econômica e social dos assentamentos beneficiados pelo programa de Reforma Agrária no município de Caucaia;

- Verificar o grau de acumulação de capital social dos assentamentos;

- Calcular o índice ambiental dos assentamentos;

- Verificar o desenvolvimento sustentável dos assentamentos.

\section{Metodologia}

\section{1. Área de Estudo e Tamanho da Amostra}

A pesquisa foi realizada nos assentamentos de reforma agrária, em Boqueirão dos Cunhas, Buíque/Poço Verde e Angicos. Os três localizados no município de Caucaia, Região Metropolitana de Fortaleza (RMF), no Estado do Ceará, tendo como indicativo o ano de 2003. Foram entrevistados 12 beneficiários para cada assentamento, totalizando 36 questionários.

\subsection{Procedimento metodológico para criação do Índice de Sustentabilidade}

No presente estudo elaborou-se um Índice de Sustentabilidade (IS) considerando um elenco de variáveis representativas de desenvolvimento econômico-social, capital social e ambiental para as comunidades de Angicos, Boqueirão dos Cunhas e Buíque/Poço Verde. Conhecer os anseios das comunidades a partir de seus problemas e potencialidades constitui para o tomador de decisões uma informação de grande relevância estratégica na formulação de políticas de desenvolvimento sustentável com a participação ativa da comunidade. Para a elaboração do Índice de Sustentabilidade foi necessária a elaboração de outros três índices, tais como desenvolvimento econômico-social, capital social e ambiental, definidos a seguir. 


\subsection{Desenvolvimento Econômico -Social (Qualidade de Vida)}

\subsubsection{Modelo Conceitual}

A qualidade de vida tem sido amplamente buscada pelos povos, das civilizações primitivas às mais desenvolvidas, expressando-se de acordo com a realidade empírica que se apresentava em dado espaço de tempo.

Buarque (1993 apud KHAN 2000), afirma que "durante séculos a qualidade de vida estava em não ser ameaçado pelos deuses, nem ser surpreendido pelas intempéries, e ter força para resistir aos inimigos naturais ou humanos. A vida era a rotina, a qualidade dela era não quebrar a rotina."

A grande contribuição se deu na quebra de paradigmas entre crescimento e desenvolvimento econômico. O aumento contínuo em termos quantitativos da renda per capita ou do Produto Interno Bruto por si só não significa desenvolvimento, uma vez que para uma nação ou região desenvolver-se, necessário se faz que atrelado ao crescimento quantitativo haja o crescimento qualitativo promovido pela alocação dos recursos econômicos para os diversos setores da sociedade, tais como educação, saúde, habitação, saneamento, emprego, distribuição eqüitativa de renda, preservação ambiental, entre outros.

Silva (2000) afirma que mesmo não existindo um conceito universal para qualidade de vida, este tema tem se constituído em preocupação mundial nos últimos anos. Para Nahas; Martins, 1996 esse conceito tem sido identificado como satisfação de um espectro de necessidades humanas básicas que assegura certo "nível de vida" a uma população.

Khan; Passos (2002) relatam que desde 1960, a Organização das Nações Unidas (ONU), vem usado o Índice de Desenvolvimento Humano (IDH), para avaliar as condições de vida nos 174 países membros da Organização. É um ranking que atribui a esses países pontuações de zero a 1, de acordo com o seu grau de desenvolvimento em três áreas: educação, renda e expectativa de vida. A partir destes indicadores é possível averiguar se as pessoas estão aptas a desfrutar dos benefícios mais subjetivos e imensuráveis do desenvolvimento, como o acesso à informação, a educação e a participação política. 
Qualquer que seja a definição a respeito do nível de qualidade de vida deve-se considerar a promoção do bem-estar do ser humano. Notadamente não se pode pensar em qualidade de vida sem antes suprir as necessidades primárias de sobrevivência (WILHEIM, 1997).

\subsection{2 Índice de Desenvolvimento Econômico Social- IDES}

Para verificar se os assentamentos de reforma agrária têm contribuído para a melhoria da qualidade de vida de seus beneficiários foi feita uma avaliação a partir de um índice resultante da agregação de indicadores como: educação, saúde, habitação, aspectos sanitários, lazer e renda.

O método utilizado neste estudo foi desenvolvido por Fernandes (1997 apud Khan 2001) e apresenta os seguintes passos: I) estabelecimento dos indicadores que constituem o índice de Desenvolvimento Econômico Social com seus respectivos escores e pesos; II) organização de postos posicionados em ordem crescente de valores, partindo-se da situação onde o indicador é menos expressivo, até a situação em que poderia atingir seu melhor desempenho.

Quanto aos pesos, estes assumiram valores de 0 a 3, para expressar a opinião dos produtores assentados na escala ascendente de posto.

Assim, matematicamente, pode-se definir o IDES como:

$$
I D E S=\frac{1}{n} \sum_{j=1}^{n}\left[\frac{\sum_{i=1}^{m} E_{i j} \cdot P_{i j}}{\sum_{i=1}^{m} E \max _{i} \cdot P \max _{i}}\right]
$$

A contribuição de cada indicador no IDES das comunidades foi obtida da seguinte maneira:

$$
C_{i}=\frac{\sum_{i=1}^{m} E_{i j} \cdot P_{i j}}{n\left(\sum_{i=1}^{m} E \max _{i} \cdot P \max _{i}\right)}
$$

Onde: IDES = Índice de Desenvolvimento Econômico-Social; Pij = Peso do i-ésimo indicador, alcançado pelo j-ésimo produtor; Pmaxi $=$ Peso máximo do i-ésimo indicador; Eij = escore do i-ésimo indicador 
obtido pela j-ésimo produtor; Emax, $\mathrm{i}=$ escore máximo do i-ésimo indicador; $\mathrm{Ci}=$ contribuição do indicador "i" no índice de desenvolvimento econômico-social dos assentados; $\mathrm{i}=1, \ldots, \mathrm{m}$, número de indicadores; $\mathrm{j}=1, \ldots, \mathrm{n}$, número de assentados.

\section{* Consolidação dos indicadores utilizados no cálculo do Índice de Desenvolvimento Econômico Social - IDES}

Será apresentada a seguir a relação dos indicadores utilizados no modelo, com os seus respectivos escores, para a aferição do índice de desenvolvimento econômico e social - IDES.

\section{I) Indicador Saúde}

Para este indicador, foi considerada a disponibilidade de serviços de saúde ao associado e sua família, tais como:

a) ausência de atendimento médico e ambulatorial (vacinação, primeiros socorros etc).

b) atendimento de primeiros socorros

c) atendimento por agente de saúde

d) atendimento médico

\section{II) Indicador de Educação}

Para este indicador, considerou-se a existência ou ausência de serviços educacionais para os assentados e família, sendo atribuídos os seguintes escores:

a) Ausência de escolas públicas ou comunitárias 0

b) Escolas de cursos de alfabetização 1

c) Escolas de ensino fundamental 2

d) Escolas de ensino médio 3

\section{III) Indicador Habitacional}

Foram considerados os seguintes aspectos habitacionais do associado pesquisado: i) tipo de construção da sua residência e ii) energia utilizada na residência, em que o resultado deste indicador será obtido pela soma dos escores, que não ultrapassa o valor 3 . 
III.1 - Tipo de construção da residência é de:

a) casa de taipa

b) casa de tijolo, sem reboco e piso. 1

c) casa de tijolo, com reboco e piso. 2

III.2 - A iluminação usada na sua residência é:

a) lampião a querosene ou a gás ou lamparina e/ou velas 0

b) energia elétrica 1

\section{IV) Indicador Condições Sanitárias e Higiene}

Este indicador foi formatado com base em três variáveis: i) destino dado os dejetos humanos; ii) tipo de tratamento dado à água para o consumo humano e iii) destino dado ao lixo domiciliar. Desta forma o indicador Condições Sanitárias e Higiene é decorrente da soma dessas três variáveis, que, assim como os indicadores anteriores, não ultrapassa o valor 3 .

IV.1 - Destino dados aos dejetos humanos

a) jogado a céu aberto ou enterrado

b) dirigido à fossa ou rede de esgoto

IV.2 - Tipo de tratamento dado à água para consumo humano

a) nenhum tratamento

b) fervida, filtrada ou com hipoclorito de sódio.

IV.3 - Destino dado ao lixo domiciliar

a) jogado ao solo ou queimado

b) enterrado ou recolhido através de coleta domiciliar

\section{V) Indicador Econômico}

Foi utilizada a renda líquida mensal da família-R (renda agropecuária + renda não agropecuária) como indicador econômico. As famílias foram divididas em três grupos a seguir:

a) $R<240,00$

b) $240,00 \leq R \leq 720,00 \quad 2$

c) $R>720,00$ 


\section{VI) Indicador Lazer}

Concernente a este indicador, o associado foi indagado a respeito do tipo de entretenimento preferido por ele e sua família, considerando-se os seguintes escores:

a) nenhuma infra-estrutura de lazer

b) existência de salões de festas ou campos de futebol 1

c) existência de campos de futebol e salões de festas 2

d) existência de campos de futebol, salões de festas e televisor. 3

Quanto mais próximo de 1, maior o valor do Índice de desenvolvimento econômico-social, IDES, nas comunidades. Optou-se por estabelecer o seguinte critério:
a)Baixo nível do indicador de desenvolvimento econômico - social
$0<\operatorname{IDES} \leq 0,5$
b)Médio nível do indicador de desenvolvimento econômico - social
$0,5<\operatorname{IDES} \leq 0,8$
c) Alto nível do indicador de desenvolvimento econômico - social
$0,8<\operatorname{IDES} \leq 1,0$

\subsection{Capital Social}

\subsubsection{Modelo Conceitual}

A partir dos anos 90, o conceito de capital social tem despertado progressivo interesse nos debates acerca do desenvolvimento econômico de países e regiões.

A introdução do conceito teve início com Putnam (1997), que associou a presença do capital social ao nível de desenvolvimento econômico. Para o autor, capital social compreende características da organização social, confiança, normas e sistemas, que contribuem para aumentar a eficiência da sociedade, facilitando as ações coordenadas. O capital social quando presente em uma sociedade, fortalece a tomada de decisões e a execução de ações colaborativas que beneficiam toda comunidade.

Monastério (2003), afirma que a definição de capital social para Coleman se distancia da de Putnam no tocante à aplicação prática, uma vez que este inclui todas as condições, através das quais as relações podem 
contribuir para a produção: desde reciprocidade e confiança mútua entre os agentes, laços horizontais, e até mesmo, organizações verticais que deliberadamente ou não resolvam problemas de ação coletiva.

Dentro deste contexto, o World Bank aborda quatro categorias de capital social: capital social como atributo individual que envolve a capacidade cooperativa, confiança, tolerância para solucionar problemas dos agentes envolvidos; capital social como associações e normas cooperativas que impliquem em benefícios para a comunidade; capital social como rede de conexões de acordo com indicações da teoria de Granovetter ${ }^{4}$; e capital social como ambiente institucional.

\subsection{2 Índice de Capital Social}

O capital social neste estudo foi elaborado a partir dos indicadores que expressam as relações interpessoais entre os membros beneficiados, pelo Programa de Reforma Agrária e sua participação em associações de caráter participativo, cooperativo e conseqüentemente canalizador de recursos destinados à promoção do desenvolvimento dos assentados e de suas famílias. A acumulação do capital social intangível dos assentados selecionados será avaliada através do Índice de Capital Social (ICS).

Assim, matematicamente, pode-se definir o ICS como:

$$
I C S=\frac{1}{n} \sum_{j=1}^{n}\left[\frac{\sum_{i=1}^{m} E_{i j}}{\sum_{i=1}^{m} E \max _{i}}\right]
$$

A contribuição de cada variável no ICS das comunidades foi obtida da seguinte maneira:

$$
C_{i}=\frac{\sum_{j=1}^{n} E_{i j}}{\sum_{i=1}^{m} \sum_{j=1}^{n} E_{\max , i}}
$$

\footnotetext{
${ }^{1}$ Para esse estudioso, os indivíduos estão inseridos numa rede de relações sociais e seus comportamentos são definidos dentro de uma malha de conexões com outros atores sociais.
} 
Em que: $\mathrm{ICS}=$ Índice de capital social; $\mathrm{E}_{\mathrm{ij}}=$ escore do i-ésimo indicador obtido pelo j-ésimo assentado; $\mathrm{E}_{\max , \mathrm{i}}=$ escore máximo da $i$ ésimo indicador; $\mathrm{C}_{\mathrm{i}}=$ contribuição do indicador " $i$ " no índice de Capital Social; $\mathrm{i}=1, \ldots ., \mathrm{m}$, número de indicadores; $\mathrm{j}=1$, ...., n, número de assentados .

\section{* Consolidação das Variáveis Utilizadas no Cálculo do Índice de Capital Social (ICS)}

Será apresentada a seguir a relação das variáveis utilizadas no modelo, com seus respectivos pesos, para a aferição do índice de capital social (ICS).

I) as pessoas sempre se interessam mais pelo seu bem-estar e de suas famílias, e não se preocupam muito com o bem-estar da comunidade -

(0) Sim e (1) Não

II) freqüenta as reuniões da associação - (0) Não e (1) Sim

III) comunicado e convidado para assistir assembléias/reuniões da associação-

(0) Não e (1) Sim

IV) participa da escolha dos líderes da associação - (0) Não e (1) Sim

V) as decisões são aprovadas em reuniões/ assembléias - (0) Não e (1) Sim

VI) apresenta sugestões nas reuniões - (0) Não e (1) Sim

VII) as decisões tomadas são efetivamente executadas pela diretoria -

(0) Não e (1) Sim

VIII) os dirigentes realizam a prestação de contas com os associados -

(0) Não e (1) Sim

IX) paga taxa mensal - (0) Não e (1) Sim

X) participa na elaboração de eventos sociais - (0) Não e (1) Sim

XI) se tiver um problema, sempre aparecerá alguém para ajudar -

(0) Não e (1) Sim

XII) desempenhou algum cargo ou teve algum tipo de responsabilidade no funcionamento de alguma entidade, associação da sua região ou da sua cidade - (0) Não e (1) Sim

Quanto mais próximo de 1, o valor do Índice de Capital Social (ICS), maior o nível de acumulação de capital social nas comunidades. Conforme Khan e Silva (2002), para verificar o nível de acumulação do capital social, optou-se por estabelecer o seguinte critério: 

a)Baixo nível de acumulação de capital social
$0<I C S \leq 0,5$
b)Médio nível de acumulação de capital social
$0,5<I C S \leq 0,8$
c) Alto nível de acumulação de capital social
$0,8<I C S \leq 1,0$

\subsection{Indicador Ambiental}

\subsubsection{Modelo Conceitual}

Nos últimos trinta anos a questão ambiental tem se constituído em um dos mais importantes temas de debates e pesquisas em todo o planeta.

A partir dos anos 1970 os efeitos da degradação ambiental já não se limitavam a tratamentos locais, frutos de ações interestaduais ou intermunicipais. Os efeitos drásticos produzidos pela devastação em um dado país ou região implicam em comprometimento global.

Segundo Rodrigues (1999), a pressão exercida pela consciência despertada, reflexo da ampla divulgação do tema, através das Conferências Mundiais sobre Meio Ambiente de 1972 e 1992, forçou a introdução definitiva das questões ambientais, desenvolvimento e cidadania, e fez com que estas questões passassem a ser compreendidas como tema de responsabilidade comum à toda humanidade, não podendo mais se restringir a uma questão de soberania nacional.

Contudo, as evidências denunciam que no Brasil há graves problemas de agressão ao meio ambiente em curso, oriundos da concentração de riquezas, fruto de um modelo econômico profundamente injusto, que amplia os índices de pobreza, semeia a ignorância, o desemprego, a violência, as doenças e mortes (NEVES; TOSTES, 1998).

No entanto, atribuir à degradação ambiental somente à pressão demográfica e à pobreza não implica em nenhum benefício para a solução do problema ambiental, uma vez que a maior emissão de poluentes, devastação e degradação têm sido implementadas pelos países industrializados e que ainda oferecem resistência à nova concepção de desenvolvimento sustentável. As estatísticas apontam que uma grande fonte de contaminação ambiental além da indústria, é o setor agrícola. 


\subsection{2 Índice Ambiental - I A}

$\mathrm{O}$ índice ambiental foi calculado através de respostas às perguntas básicas referentes às comunidades. Conforme PEREIRA (2001), uma justificativa para o índice de sustentabilidade ambiental seria a seguinte: a pergunta referente à preservação ou à recuperação do solo é uma questão básica, ou seja, qualquer atividade agrícola que destrua o solo, seja a curto ou em longo prazo, não pode de forma alguma ser considerada uma atividade que esteja de acordo com o conceito e a prática de desenvolvimento sustentável. A biodiversidade é outra questão importante, pois sua redução gera implicações bastante sérias sobre o equilíbrio ambiental; como, caso extremo, tem-se a monocultura que está mais exposta ao ataque de pragas, devido a uma redução da biodiversidade e, por isso, se torna mais dependente de agrotóxicos. Portanto, este aspecto representa um fator negativo em termos de sustentabilidade ambiental.

Assim, matematicamente, pode-se definir o IA como:

$$
I A=\frac{1}{n} \sum_{j=1}^{n}\left(\frac{1}{m} \sum_{i=1}^{m}\left(E_{i j} / E_{\text {max }, i}\right)\right)
$$

A contribuição de cada variável no IA das comunidades foi obtida da seguinte maneira:

$$
C_{i}=\frac{\sum_{j=1}^{n} E_{i j}}{\sum_{i=1}^{m} \sum_{j=1}^{n} E_{\mathrm{max}, i}}
$$

Em que: $\mathrm{IA}=$ Índice Ambiental; $\mathrm{E}_{\mathrm{ij}}=$ escore da $i$-ésimo indicador obtida pela j-ésimo associado; $\mathrm{E}_{\max , \mathrm{i}}=$ escore máximo da $i$ ésimo indicador; $\mathrm{C}_{\mathrm{i}}=$ contribuição do indicador " $i$ " no índice Ambiental; $\mathrm{i}=1, \ldots . \mathrm{m}$, número de indicadores; $\mathrm{j}=1, \ldots$, n, número de assentados. 


\section{* Consolidação das Variáveis Utilizadas no Cálculo do Índice Ambiental (IA)}

Será apresentada a seguir a relação das variáveis utilizadas no modelo, com seus respectivos pesos, para a aferição do índice ambiental (IA).

I) Método de controle de pragas utilizado na unidade produtiva-

(0) Agrotóxico (1) Nenhum método (2) Biológico

II) faz utilização de fogo nas atividades agropecuárias - (0) Sim e (1) Não

III) faz plantio de árvores para fins de conservação de solos -

(0) Não e (1) Sim

IV) existe área de reserva de mata nativa na propriedade - (0) Não e (1) Sim

V) utiliza prática de plantio para evitar a degradação do solo -

(0) Não e (1) Sim

VI) casa com sistema de esgoto ou algum tipo de fossa - (0) Não e (1) Sim

VII) faz rotação de cultura - (0) Não e (1) Sim

VIII) se necessário, faz calagem - (0) Não e (1) Sim

IX) usa esterco animal - (0) Não e (1) Sim

X) utiliza o solo de acordo com a sua vocação - (0) Não e (1) Sim

Quanto mais próximo de 1, o valor do IA, maior o índice ambiental nas comunidades. Optou-se por estabelecer o seguinte critério:
a)Baixo nível do indicador ambiental
$0<I A \leq 0,5$
b)Médio nível do indicador ambiental
$0,5<I A \leq 0,8$
c) Alto nível do indicador ambiental
$0,8<I A \leq 1,0$

\subsection{Sustentabilidade}

\subsubsection{Modelo Conceitual}

Nas últimas décadas, a preocupação sobre os riscos com a degradação ambiental fez surgir uma série de debates e conferências que culminaram com o conceito de desenvolvimento sustentável, como o novo paradigma de desenvolvimento, uma vez que os tradicionais modelos existentes já não correspondiam à nova ordem global.

As discussões sobre esse tema culminaram em 1987, com a publicação 
do Relatório intitulado Our Common Future e através dele é conceituado o desenvolvimento sustentável como sendo "o atendimento das necessidades do presente sem, no entanto, comprometer a capacidade de as gerações futuras terem as suas também satisfeitas" (NOSSO FUTURO COMUM, 1991).

Não obstante a realização de reuniões, conferências e estudos desenvolvidos até hoje, a definição de desenvolvimento sustentável ou sustentabilidade, envolve muitas dimensões do conhecimento, o que torna mais abrangente essa conceituação.

O Ministério para o Desenvolvimento Internacional (DFID), (2003), conceitua as muitas dimensões de sustentabilidade distinguindo os aspectos ambientais, econômicos, sociais e institucionais dos sistemas sustentáveis. A sustentabilidade ambiental é alcançada quando a produtividade dos recursos naturais que sustentam a vida é preservada ou ampliada para uso das gerações futuras. A sustentabilidade econômica, no caso das populações carentes, é alcançada se um nível básico de bem-estar econômico for atingido ou mantido. A sustentabilidade social é alcançada quando a exclusão social é minimizada e a igualdade social maximizada. A sustentabilidade institucional é alcançada quando as estruturas e os processos preponderantes têm condições de continuar a desempenhar suas funções a longo prazo.

Em 1992, a Conferência da Organização das Nações Unidas (ONU) sobre Meio Ambiente e Desenvolvimento (UNCED), enfatizou a necessidade de definição de indicadores para mensurar o nível de sustentabilidade de países e regiões. (PEREIRA, 2001).

\subsection{2. Índice de Sustentabilidade (IS)}

Os indicadores que serão utilizados para medir a sustentabilidade no presente trabalho estão divididos em três: Indicador de Desenvolvimento Econômico-Social; Indicador Ambiental e Indicador de Capital Social.

Dentro desta visão foi desenvolvido o seguinte Índice de Sustentabilidade (IS):

$$
I S=\frac{1}{k} \sum_{h=1}^{k} I_{h}
$$

Em que: IS = Índice de Sustentabilidade;

$$
\mathrm{I}=\text { valor do } h \text {-ésimo índice; } \mathrm{h}=1, \ldots, \mathrm{k}
$$


O valor do Índice de Sustentabilidade é a média aritmética dos três índices citados anteriormente, quanto mais próximo de 1, maior o indicador de sustentabilidade nas comunidades. $\mathrm{O}$ indicador está dentro do intervalo: $0<I S \leq 1$

Optou-se por estabelecer o seguinte critério:
a)Baixo nível de sustentabilidade
$0<I S \leq 0,5$
b)Médio nível de sustentabilidade
$0,5<I S \leq 0,8$
c)Alto nível de sustentabilidade
$0,8<I S \leq 1,0$

\section{Resultados e discussão}

Os indicadores observados neste estudo para delinear o grau de sustentabilidade dos beneficiados pelo programa de reforma agrária, bem como aos índices de desenvolvimento econômico e social, capital social e ambiental, são apresentados e discutidos a seguir.

\section{1. Índice de Desenvolvimento Econômico e Social (IDES) dos Assentamentos}

Na composição do IDES dos assentados estudados, Tabela 1, observa-se que nos assentamentos de Boqueirão dos Cunhas, Buíque/ Poço Verde e Angicos, a contribuição do indicador de Habitação com valores respectivos de 0,1528; 0,1528 e 0,1597, supera a dos demais indicadores na formação do IDES. Neste caso, o tipo de construção ou, mais precisamente, a existência de moradias com reboco e piso e o acesso à energia elétrica, foram fatores predominantes no grau de satisfação dos produtores e, conseqüentemente, no bom desempenho do indicador Habitação no IDES. 
Tabela 1 - Participação absoluta e relativa dos indicadores sócio-econômicos na composição de IDES nos assentamentos de reforma agrária no município de Caucaia - CE, 2003.

\begin{tabular}{l|c|c|c|c|c|c|cc}
\hline \multicolumn{1}{|c}{ Indicador } & \multicolumn{1}{c}{$\begin{array}{c}\text { Boqueirão dos } \\
\text { Cunhas }\end{array}$} & \multicolumn{2}{c}{$\begin{array}{c}\text { Buíque/ Poço } \\
\text { Verde }\end{array}$} & \multicolumn{2}{c}{ Angicos } & \multicolumn{2}{c}{ Amostra Total } \\
\cline { 2 - 10 } & V. A. & V. R. & V. A. & V. R. & V. A. & V. R. & V. A. & V. R. \\
\hline Saúde & 0,1111 & 19,32 & 0,1111 & 25,00 & 0,1111 & 18,82 & 0,1111 & 20,70 \\
Educação & 0,1111 & 19,32 & 0,0000 & 0,00 & 0,1111 & 18,82 & 0,0741 & 13,80 \\
Habitação & 0,1528 & 26,56 & 0,1528 & 34,38 & 0,1597 & 27,06 & 0,1551 & 28,90 \\
Aspectos & 0,0799 & 13,88 & 0,0694 & 15,63 & 0,0833 & 14,12 & 0,0775 & 14,45 \\
sanitários & & & & & & & & \\
Lazer & 0,0000 & 0,00 & 0,0000 & 0,00 & 0,0000 & 0,00 & 0,0000 & 0,00 \\
Econômico & 0,1204 & 20,93 & 0,1111 & 25,00 & 0,1250 & 21,18 & 0,1188 & 22,14 \\
\hline IDES & 0,5752 & 100,00 & 0,4444 & 100,00 & 0,5903 & 100,00 & 0,5367 & 100,00 \\
\hline
\end{tabular}

Fonte: Dados da pesquisa; Nota: V. A. - Valores Absolutos; V. R. - Valores Relativos.

Considerando a amostra total, o indicador Habitação destacou-se como o de maior participação no IDES geral, com, 0,1551, equivale a $28,90 \%$ em relação ao total de 0,5367. Considerando-se o IDES de cada assentamento, observa-se que Angicos foi o que apresentou maior índice 0,5903, enquanto Buíque/Poço Verde foi o de menor IDES, com 0,4444. Os assentamentos de Boqueirão dos Cunhas e Angicos apresentaram um médio nível de desenvolvimento econômico-social, enquanto o assentamento de Buíque/Poço Verde apresentou um baixo nível deste. Um dos fatores que pode ter contribuído para o baixo nível de desenvolvimento econômico-social de Buíque/Poço Verde é a inexistência de serviços de educação no assentamento, que beneficiem seus moradores.

Na composição do IDES dos assentamentos, Tabela 1, observa-se que em Boqueirão dos Cunhas, Buíque/Poço Verde e em Angicos o segundo indicador com maior participação foi o Indicador Econômico, tendo contribuído com valores respectivos de 0,1204; 0,1111 e 0,1250. Cabe ressaltar que em Angicos os valores de renda são superiores aos demais assentamentos pesquisados.

\section{2. Índice de Capital Social dos Assentamentos (ICS)}

Na composição do Índice de Capital Social, conforme dados constantes da Tabela 2, observa-se que o assentamento de Boqueirão dos 
Cunhas apresenta o maior índice, com 0,7949, enquanto em Angicos foi de 0,6795 e Buíque/Poço Verde 0,7692. Assim, todos os assentamentos apresentaram um médio nível de capital social. Indicadores como não aceitação de sugestões pela diretoria e não cobrança de taxa mensal foram os principais responsáveis pelo menor nível de acumulação de capital do assentamento de Angicos

Tabela 2 - Participação absoluta e relativa dos indicadores de capital social na composição do ICS nos assentamentos estudados no município de Caucaia - CE, 2003.

\begin{tabular}{|c|c|c|c|c|c|c|c|c|}
\hline \multirow{3}{*}{ Indicador } & \multicolumn{6}{|c|}{ Município } & \multirow{2}{*}{\multicolumn{2}{|c|}{ Amostra Tota }} \\
\hline & \multicolumn{2}{|c|}{$\begin{array}{l}\text { Boqueirão dos } \\
\text { Cunhas }\end{array}$} & \multicolumn{2}{|c|}{ Angicos } & \multicolumn{2}{|c|}{$\begin{array}{c}\text { Buíque/ } \\
\text { Poço Verde }\end{array}$} & & \\
\hline & V. A. & V. R. & V. A. & V. R. & V. A. & V. R. & V. A. & V. R. \\
\hline $\begin{array}{l}\text { O interesse é maior pelo } \\
\text { bem-estar individual }\end{array}$ & 0,0577 & 7,26 & 0,0449 & 6,60 & 0,0641 & 8,33 & 0,0556 & 7,43 \\
\hline Participa nas reuniões & 0,0769 & 9,68 & 0,0705 & 10,38 & 0,0769 & 10,00 & 0,0748 & 10,00 \\
\hline $\begin{array}{l}\text { É comunicado sobre as } \\
\text { reuniões }\end{array}$ & 0,0769 & 9,68 & 0,0769 & 11,32 & 0,0705 & 9,17 & 0,0748 & 10,00 \\
\hline $\begin{array}{l}\text { Participa da escolha dos } \\
\text { líderes }\end{array}$ & 0,0641 & 8,06 & 0,0641 & 9,43 & 0,0769 & 10,00 & 0,0684 & 9,14 \\
\hline $\begin{array}{l}\text { Decisões são aprovadas em } \\
\text { reuniōes }\end{array}$ & 0,0705 & 8,87 & 0,0705 & 10,38 & 0,0769 & 10,00 & 0,0726 & 9,71 \\
\hline Apresentação de sugestões & 0,0577 & 7,26 & 0,0641 & 9,43 & 0,0641 & 8,33 & 0,0620 & 8,29 \\
\hline $\begin{array}{l}\text { Decisões tomadas são } \\
\text { executadas pela diretoria }\end{array}$ & 0,0577 & 26 & 0641 & 9,43 & 0,0705 & 9,17 & 0,0641 & 8,57 \\
\hline Aceitação de sugestões & 0,0705 & 8,87 & 0,0449 & 6,60 & 0,0577 & 7,50 & 0,0577 & 7,71 \\
\hline Prestação de contas & 0,0769 & 9,68 & 0,0641 & 9,43 & 0,0577 & 7,50 & 0,0662 & 8,86 \\
\hline Paga taxa mensal & 0,0705 & 8,87 & 0,0000 & 0,00 & 0,0641 & 8,33 & 0,0449 & 6,00 \\
\hline Elabora eventos sociais & 0,0321 & 4,03 & 0,0192 & 2,83 & 0,0064 & 0,83 & 0,0192 & 2,57 \\
\hline $\begin{array}{l}\text { Para problemas, sempre } \\
\text { aparece ajuda. }\end{array}$ & 0,0577 & 7,26 & 0,0449 & 6,60 & 0,0641 & 8,33 & 0,0556 & 7,43 \\
\hline $\begin{array}{l}\text { Assumiu algum cargo na } \\
\text { associação }\end{array}$ & 0,0256 & 3,23 & 0,0513 & 7,55 & 0,0192 & 2,50 & 0,0321 & 4,29 \\
\hline ICS & 0,7949 & 100,00 & 0,6795 & 100,00 & 0,7692 & 100,00 & 0,7479 & 100,00 \\
\hline
\end{tabular}

Fonte: Dados da pesquisa

Para a amostra total os indicadores de maior participação foram: freqüência às reuniões e comunicação sobre as reuniões, ambos com uma participação de 0,0748, no ICS geral de 0,7479. O indicador de menor participação no ICS geral foi elaboração de eventos sociais, com uma participação de 0,0192. Em Boqueirão dos Cunhas, os indicadores mais 
representativos na formação do ICS foram: freqüência nas reuniões; comunicação sobre as reuniões e a prestação de contas aos assentados, com 0,0769. Em Angicos, a comunicação sobre as reuniões é o indicador de maior participação no ICS, com 0,0769. Em Buíque /Poço Verde a freqüência nas reuniões, comunicação sobre as reuniões e as decisões que são apreciadas e aprovadas nas reuniões, foram os indicadores com maior participação na formação do ICS, com 0,0769.

\section{3. Índice Ambiental dos Assentamentos (IA)}

Na formação deste índice, conforme Tabela 3, observou-se que o indicador de existência de área de reserva nativa foi o que teve a segunda maior contribuição no Índice Ambiental geral dos assentados pesquisados, com valores de 0,1000 para Boqueirão dos Cunhas; 0,0917 para Angicos e 0,1000 para Buíque /Poço Verde. Os três assentamentos mantêm a exigência legal de preservação ambiental de $20 \%$ da área total dos assentamentos.

Tabela 3- Participação absoluta e relativa dos indicadores ambientais na composição do IA nos assentamentos no município de Caucaia - CE, 2003.

\begin{tabular}{|c|c|c|c|c|c|c|c|c|}
\hline \multirow{3}{*}{ Indicador } & \multicolumn{6}{|c|}{ Município } & \multirow{2}{*}{\multicolumn{2}{|c|}{ Amostra Total }} \\
\hline & \multirow{2}{*}{\begin{tabular}{|c|}
$\begin{array}{c}\text { Boqueirão } \\
\text { dos Cunhas }\end{array}$ \\
V. A . \\
\end{tabular}} & \multirow[b]{2}{*}{ V. R. } & \multirow{2}{*}{\begin{tabular}{|c|} 
Angicos \\
V. A . \\
\end{tabular}} & \multirow[b]{2}{*}{ V. R. } & \multirow{2}{*}{\begin{tabular}{|c|}
$\begin{array}{c}\text { Buíque/ } \\
\text { Poço Verde }\end{array}$ \\
V. A . \\
\end{tabular}} & \multirow[b]{2}{*}{ V.R. } & & \\
\hline & & & & & & & V. A. & V. R. \\
\hline Controle de pragas & 0,0208 & 3,70 & 0,0208 & 4,67 & 0,0458 & 8,40 & 0,0292 & 5,63 \\
\hline $\begin{array}{l}\text { Uso de queimadas nas } \\
\text { atividades agropecuárias }\end{array}$ & 0,0167 & 2,96 & 0,0583 & 13,08 & 0,0083 & 1,53 & 0,0278 & 5,36 \\
\hline $\begin{array}{l}\text { Planta árvores para } \\
\text { conservação de solos }\end{array}$ & 0,0583 & 10,37 & 0,0250 & 5,61 & 0,0500 & 9,16 & 0,0444 & 8,58 \\
\hline Área de reserva nativa & 0,1000 & 17,78 & 0,0917 & 20,56 & 0,1000 & 18,32 & 0,0972 & 18,77 \\
\hline $\begin{array}{l}\text { Prática de plantio contra } \\
\text { a degradação do solo }\end{array}$ & 0,0250 & 4,44 & 0,0083 & 1,87 & 0,0667 & 12,21 & 0,0333 & 6,43 \\
\hline Existe fossa na casa & 0,1000 & 17,78 & 0,1000 & 22,43 & 0,1000 & 18,32 & 0,1000 & 19,30 \\
\hline Rotação de culturas & 0,0583 & 10,37 & 0,0167 & 3,74 & 0,0583 & 10,69 & 0,0444 & 8,58 \\
\hline Faz calagem & 0,0083 & 1,48 & 0,0167 & 3,74 & 0,0083 & 1,53 & 0,0111 & 2,14 \\
\hline Usa esterco animal & 0,0833 & 14,81 & 0,0417 & 9,35 & 0,0417 & 7,63 & 0,0556 & 10,72 \\
\hline $\begin{array}{l}\text { Utilização de solo de } \\
\text { acordo com sua vocação }\end{array}$ & 0,0917 & 16,30 & 0,0667 & 14,95 & 0,0667 & 12,21 & 0,0750 & 14,48 \\
\hline IA & 0,5625 & 100,00 & 0,4458 & 100,00 & 0,5458 & 100,00 & 0,5181 & 100,00 \\
\hline
\end{tabular}

Fonte: Dados da pesquisa. Nota: V. A . - Valores Absolutos; V. R. - Valores Relativos. 
Fazer calagem, quando há necessidade é o indicador de menor participação no Indicador Ambiental dos assentados de Boqueirão dos Cunhas e Buíque/Poço Verde, ambos com 0,0083, respectivamente, enquanto em Angicos destaca-se com menor contribuição, prática de plantio contra a degradação do solo com 0,0083. O índice ambiental geral foi de 0,5181, destacando-se com maior participação a existência de fossas sépticas, com 0,1000, ou 19,30\% do total e menor contribuição, fazer calagem quando há necessidade, com índice de 0,0111, correspondendo a 2,14\% do IA geral.

$\mathrm{O}$ assentamento de Boqueirão dos Cunhas apresentou um indicador ambiental de 05642, o assentamento de Buíque Poço Verde 0,5458 e Angicos 0,4458. Os assentamentos de Boqueirão dos Cunhas e Buíque/Poço Verde apresentaram um médio nível ambiental enquanto o assentamento de Angicos apresentou baixo nível de sustentabilidade ambiental.

\section{4. Índice de Sustentabilidade dos Assentamentos}

Analisando a contribuição de cada indicador na formação do Índice de Sustentabilidade para amostra total, conforme Tabela 4, verifica-se uma tendência de desequilíbrio entre o indicador de capital social e os demais, a participação do indicador de capital social é bem superior em relação à participação dos índices de Desenvolvimento Econômico-Social e Ambiental, respectivamente 0,2493, 0,1789 e 0,1727 em valores absolutos.

Tabela 4 - Participação absoluta e relativa dos índices na composição do índice de sustentabilidade nos assentamentos no município de Caucaia - CE, 2003.

\begin{tabular}{|c|c|c|c|c|c|c|c|c|}
\hline \multirow{3}{*}{ Índice } & \multicolumn{6}{|c|}{ Municípios } & \multirow{2}{*}{\multicolumn{2}{|c|}{ Amostra Total }} \\
\hline & $\begin{array}{l}\text { Boqueirão } \\
\text { dos Cunhas }\end{array}$ & & Angicos & & $\begin{array}{c}\text { Buíque/ } \\
\text { Poço Verde }\end{array}$ & & & \\
\hline & V. A. & V. R. & V. A. & V. R. & V. A. & V. R. & V. A. & V. R. \\
\hline Econômico-Social & 0,1917 & 29,76 & 0,1968 & 34,41 & 0,1481 & 25,26 & 0,1789 & 29,77 \\
\hline Capital Social & 0,2650 & 41,14 & 0,2265 & 39,60 & 0,2564 & 43,72 & 0,2493 & 41,49 \\
\hline Ambiental & 0,1875 & 29,11 & 0,1486 & 25,98 & 0,1819 & 31,02 & 0,1727 & 28,74 \\
\hline IS & 0,6442 & 100,00 & 0,5719 & 100,00 & 0,5864 & 100,00 & 0,6008 & 100,00 \\
\hline
\end{tabular}

Fonte: Dados da pesquisa. Notas: V. A . - Valores Absolutos; V. R. - Valores Relativos.

Nos assentamentos de Boqueirão dos Cunhas, Angicos e Buíque/Poço Verde, a contribuição do indicador de capital social foi respectivamente, 0,2650, 0,2265 e 0,2564. Talvez o elevado índice de contribuição justifi- 
que-se pela iniciativa de planejamento das atividades se constituir um fator preponderante para qualquer atividade. O índice de menor participação de sustentabilidade verificado nos assentamentos de Boqueirão dos Cunhas e Angicos foi o índice ambiental, com valores absolutos de 0,1875 e 0,1486, respectivamente. Já para Buíque/Poço Verde o índice de menor participação foi o Econômico-Social com um valor de 0,1481, onde os assentados têm menor nível de renda em relação a outros assentamentos e também não têm acesso à educação.

$O$ índice de sustentabilidade para os assentamentos de Boqueirão dos Cunhas; Buíque/Poço Verde e Angicos, foram respectivamente, 0,6442; 0,5864 e 0,5719 . Os três assentamentos apresentaram um médio nível de sustentabilidade. Sendo que no computo geral o índice de sustentabilidade foi de 0,6008. De forma curiosa o assentamento de Angicos apresentou um índice de Capital Social e Ambiental mais baixo que os outros dois assentamentos. É importante ressaltar que nenhuma das comunidades obteve um alto nível de sustentabilidade e que o assentamento de Angicos tem a menor sustentabilidade dos assentamentos pesquisados e Boqueirão dos Cunhas a maior.

\section{Conclusões e sugestões}

Os indicadores de habitação, econômico e aspectos sanitários apresentaram, em ordem decrescente, as principais contribuições na composição do Índice de Desenvolvimento Econômico-Social (IDES). Ao passo que indicadores como educação e lazer, essenciais para o desenvolvimento e bem-estar do ser humano, apresentaram os piores resultados.

$\mathrm{O}$ aspecto econômico-social foi satisfatório, pelos aspectos abordados, pois a maioria dos beneficiários apresentou condições satisfatórias de qualidade de vida, apesar de a renda não-agropecuária ser bem superior à renda agropecuária, o que pode ser explicado pelo acesso dos beneficiários aos programas como bolsa escola/alimentação e vale gás além do número de aposentados nos assentamentos. Os assentamentos de Boqueirão dos Cunhas e Angicos apresentaram um médio nível do IDES enquanto o assentamento de Buíque/Poço Verde apresentou um baixo nível.

$\mathrm{O}$ aspecto ambiental apresentou resultados pouco satisfatórios, mostrando-se que, em termos ambientais, os assentados seguem práticas 
pouco sustentáveis, demonstrando que este quesito não foi atingido pelos programas. Os assentamentos de Boqueirão dos Cunhas e Buíque/ Poço Verde apresentaram um médio nível do indicador ambiental, enquanto Angicos apresentou baixa sustentabilidade ambiental.

O valor do Índice de Capital Social demonstrou que as associações possuem um médio de acumulação de capital social nas comunidades. Os assentados participam da tomada de decisões, dando sugestões que, deve-se frisar, são bem aceitas pela diretoria, mostrando assim, o seu espírito democrático. Todos os assentamentos apresentaram um médio nível do capital social.

Conclui-se que os assentamentos de Buíque/ Poço Verde e Angicos apresentam um índice de sustentabilidade semelhante, enquanto o assentamento de Boqueirão dos Cunhas é o que apresenta-se como o mais sustentável. Todos os assentamentos apresentaram um médio nível de sustentabilidade.

É crucial a orientação das políticas voltadas para educação e a saúde nos assentamentos, pois a contribuição dessas variáveis foi a mais baixa no índice de desenvolvimento econômico e social.

Considera-se importante proporcionar alguns cursos relativos a associativismo para todos os assentados e sobre a organização, especialmente, para os dirigentes ou lideres das associações.

\section{Referências bibliográficas}

KHAN, A. S. Reforma Agrária Solidária e Modelo de Desenvolvimento Rural no Estado do Ceará. Relatório Técnico/UFC, Fortaleza. 52p. 2000.

KHAN, A. S. Reforma agrária solidária e qualidade de vida dos beneficiários no Estado do Ceará. Revista de Economia e Sociologia Rural. v. 39, n. 4, out./dez., 2001. p.93-117.

KHAN, A. S.; SILVA, L.M. R.. Avaliação do Projeto São José no Estado do Ceará: Estudo de Caso. UFC/CCA/DEA, Fortaleza, Ceará, 2002.

KHAN, A. S., PASSOS, A. T. B. Reforma agrária solidária, assistência técnica e desenvolvimento rural no Estado do Ceará. Revista Econômica do Nordeste, Fortaleza, v. 33, n. 3, jul-set. 2002. p.593-614.

MONASTÉRIO, L. M. Putnam no pampa: capital social e a metade sul 
do Rio Grande do Sul. Disponível em: < http://www.capitalsocial.cbj. net > . Acesso: 10 abr 2003.

NAHAS, M. I. P.; MARTINS, V. L. A. B. O índice de qualidade de vida urbano (IQVU/BH): a elaboração de um novo instrumento de gestão municipal. In: ENCONTRO ANUAL DE PÓS-GRADUAÇÃO EM ADMINISTRAÇÃO. 18, 1995. João Pessoa. Anais... p. 125-219, 1996.

NEVES, E. TOSTES, A. Meio ambiente: a Lei em suas mãos. 3. ed. Petrópolis: Vozes, 1998.

NOSSO Futuro Comum/Comissão Mundial sobre Meio Ambiente e Desenvolvimento. 2.ed. Rio de Janeiro: Fundação Getúlio Vargas, 1991.

PEREIRA, N. L. Análise da sustentabilidade da produção do algodão orgânico: o caso do município de Tauá. 152 fs. Dissertação (Mestrado em Economia Rural), Departamento de Economia Agrícola do Centro de Ciências Agrárias, Universidade Federal do Ceará. Fortaleza, 2001.

PUTNAM, R. D. Comunidade e democracia: a experiência da Itália moderna. Rio de Janeiro: Fundação Getúlio Vargas. 1997.

RODRIGUES, G. M. A. A proteção das florestas tropicais como tema de segurança internacional. In: CONGRESSO INTERNACIONAL DE DIREITO AMBIENTAL, 3, 30 maio a 02 jul. 1999, São Paulo. Anais... São Paulo: IMESP, 1999. 272p. p.165-172.

SILVA, A. K. de M. da. Perfil sócio-econômico e nível de qualidade de vida dos produtores rurais do município de Mossoró-RN. 55 fs. Monografia, (Graduação em Engenharia Agronômica), Escola Superior de Agricultura de Mossoró-ESAM, Mossoró, 2000.

UNICAMP. Estudo de Avaliação de Impacto do Programa Cédula da Terra/2001. Campinas-SP, UNICAMP, 2002.

WILHEIM, J. O substantivo e o adjetivo. São Paulo: Perspectiva, 1997.

WORLD BANK. Brazil. Poverty Reduction, Growth, and Fiscal Stability in the State of Ceará. [S.I.], [S.n.], 1999. v. 1. (Policy Report). Document of the World Bank (mimeo).

Recebido em agosto de 2004 e revisto em setembro de 2004. 